\title{
Acoustic Absorption of Mortar Composites with Waste Material
}

\author{
Marco Aurélio STUMPF GONZÁLEZ, Fernanda FLACH, \\ Josiane RESCHKE PIRES, Marlova PIVA KULAKOWSKI \\ Civil Engineering Graduate Program (PPGEC), Universidade do Vale do Rio dos Sinos \\ Av. Unisinos, 950, 93022-000 — São Leopoldo, RS, Brazil; \\ e-mail:mgonzalez@unisinos.br; fernanda_flach@hotmail.com.br; josianepires@uol.com.br; marlovak@unisinos.br
}

(received September 11, 2012; accepted March 21, 2013)

\begin{abstract}
This paper presents an investigation about acoustic absorption of mortars with partial replacement of sand by waste (plywood formwork, rice husk, and thermoplastic shoe counters), examining different levels of replacement $(0 \%, 5 \%, 10 \%, 25 \%$, and $50 \%)$. The measurement of acoustic absorption was performed using a plane wave impedance tube with $100 \mathrm{~mm}$ diameter, using mortar samples of $20 \mathrm{~mm}$, in frequency range 200-2000 Hz. Results demonstrated that some composite with waste presented noise reduction coefficient $(\mathrm{NRC})$ above the reference mortar $(\mathrm{NRC}=0.0343)$, such as a composite with $50 \%$ rice husk $(\mathrm{NRC}=0.2757)$ and other with $50 \%$ of plywood waste $(\mathrm{NRC}=0.2052)$. Since there is virtually no cost or difficulty to use these residuals, it may be concluded that it is a sustainable alternative to improve the acoustic comfort and reduce the impact of the waste on the environment.
\end{abstract}

Keywords: acoustics, comfort, impedance tube, civil construction, waste.

\section{Introduction}

The quality of human life is aided by environmental conditions of comfort, such as thermal, acoustic, and luminous comforts. Noise can affect general comfort, sleep, and relationships between residents of the same building. Exposure to excessive noise for long periods can cause side effects such as interference in task performance and health problems: irritability, hypertension, headaches, insomnia, and stress (ABNT, 2010; Ferraz, 2008; Gerges, 2000).

Studies developed in Brazil show low acoustic insulation in buildings or some of its components (Duarte, Viveiros, 2007; Losso, Viveiros, 2004; Polli, Viveiros, 2007; Vianna, Roméro, 2002). Traditional solutions involve the increased thickness of slabs and the walls or insertion of special material for insulation and acoustic conditioning. Correction after construction finished usually is uneconomical, and even the expansion of the insulation in the design phase is difficult, due to the cost of traditional materials (Ferraz, 2008; Gerges, 2000; Porges, 1977).

On the other hand, construction industry is absorbing huge waste of the construction and other industries, for example through the inclusion of waste in bricks, mortar, and concrete, and so creating more sustainable materials. The replacement of part of aggregates or cement reduces the extraction of raw materials and reduces the energy consumed to produce the materials of construction (RochA, John, 2003; MEHTA, MonTEIRO, 2006).

Composites are materials made from the union of two or more elements in order to create a material with properties superior to those of their components alone. Mortars and concrete are the most common building materials worldwide (MentA, Monteiro, 2006). Composites originated from mortars and concretes may receive mineral, synthetic, and biomass fibers or particles. Some studies examine the acoustic absorption of materials produced from the recycling or recovery of materials. BRANCO et al. (2010) produced mortars using different types of lightweight aggregate (expanded polystyrene, expanded clay, and expanded granulated cork), evaluating their performance in reducing noise levels caused by impact. RAMIS et al. (2010) used hemp fibers. SAKAmoto et al. (2011) examined rice husk, rice straw, and wheat husks. DEL REY et al. (2011) worked with polyester wool obtained by recycling PET bottles. TUTIKIAN et al. (2012) investigated the noise performance of a composite ma- 
terial with recycled aggregates, ethylene vinyl acetate (EVA), as a substitute for conventional coarse aggregate in the production of lightweight concrete to use in subfloors in residential buildings. YANG et al. (2003) studied composites of rice husk and wood particles. ERSOY and KüÇÜK (2009) examined tea-leaf fibers and Oldham et al. (2011) investigated several vegetal fibers, such as jute, sisal, flax, ramie, and hemp.

One alternative that has been studied in construction is the generation of new materials, combining common materials with waste. The region of study (Vale do Rio dos Sinos, Rio Grande do Sul, Southern Brazil) has difficulty to dispose some residuals, in particular: formwork to concrete made with plywood, rice husk, and shoe counters. About $80 \%$ of plywood used in formwork for structure become waste (MOSMANN, 2012). Brazil produced 11.3 million tons of rice in 2010, and husk represents about $20 \%$ of the rice grain (Brazilian Institute for Statistics [IBGE], 2010; KIELING, 2009). Moreover, the region is a center of shoe production, generating several residues, such as EVA (already studied in acoustic applications by TUTIKIAN et al., 2012) and shoe counters (this part goes behind the heel and is used to reinforce the back part of the shoe, and to mould its structure) (KAZMIERCZAK et al., 2003).

This paper investigates the acoustic absorption in mortars produced with the addition of plywood waste, rice husk, and residuals of shoes. The methodology adopted is based on measuring samples in the impedance tube.

\section{Materials and methods}

Residues investigated were plywood resin, rice husk, and thermoplastic impregnated shoe counters. Mortar composites were investigated with partial replacement of sand by the waste, by volume $(0 \%, 5 \%$, $10 \%, 25 \%$, and $50 \%$ ). The impedance tube was evaluated as the most appropriate test method to perform the experiment, because it is necessary only a small sample of the material analyzed which allows testing with a greater quantity and variety of composites. Absorption coefficients were studied in the frequency range $200-2000 \mathrm{~Hz}$. The measurements follow international standards ASTM E1050:2008 and ISO 105342:1998. The Noise Reduction Coefficient (NRC) was then obtained by calculating the average sound absorption coefficients at $250 \mathrm{~Hz}, 500 \mathrm{~Hz}, 1000 \mathrm{~Hz}$, and $2000 \mathrm{~Hz}$ frequencies according to procedure ASTM C423-99A, but using 4 decimal places.

\subsection{Preparation of the waste}

Waste of plywood and shoe counters was cleaned and then ground in a knife mill. The particles were crushed. Figures 1 and 2 illustrate these materials. Time and effort to preparation are relatively small.

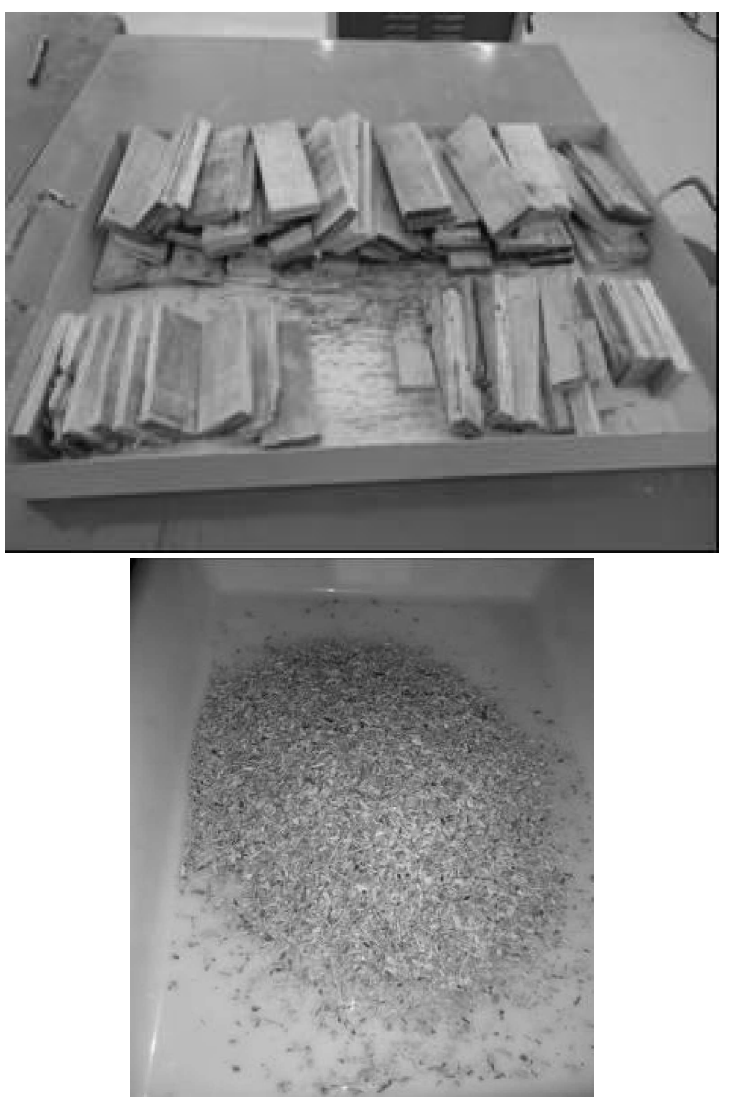

Fig. 1. Residue of plywood resin formwork: cut-off plates (top) and after grinding (bottom).

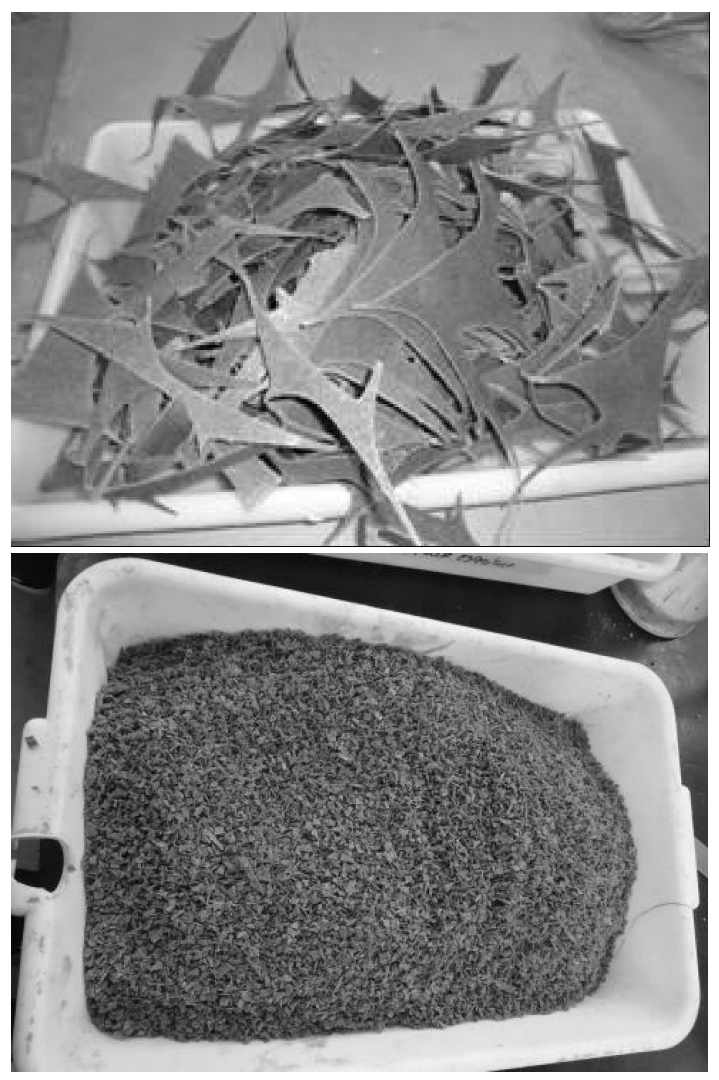

Fig. 2. Counter thermoplastic residue: waste received (top) and after grinding (bottom). 
The preparation of rice husk residue consisted of verifying and segregate foreign particles manually, through the prior selection by removing impurities such as traces of gravel, straw, etc. (Fig. 3). Also in this case waste preparation is a simple activity.
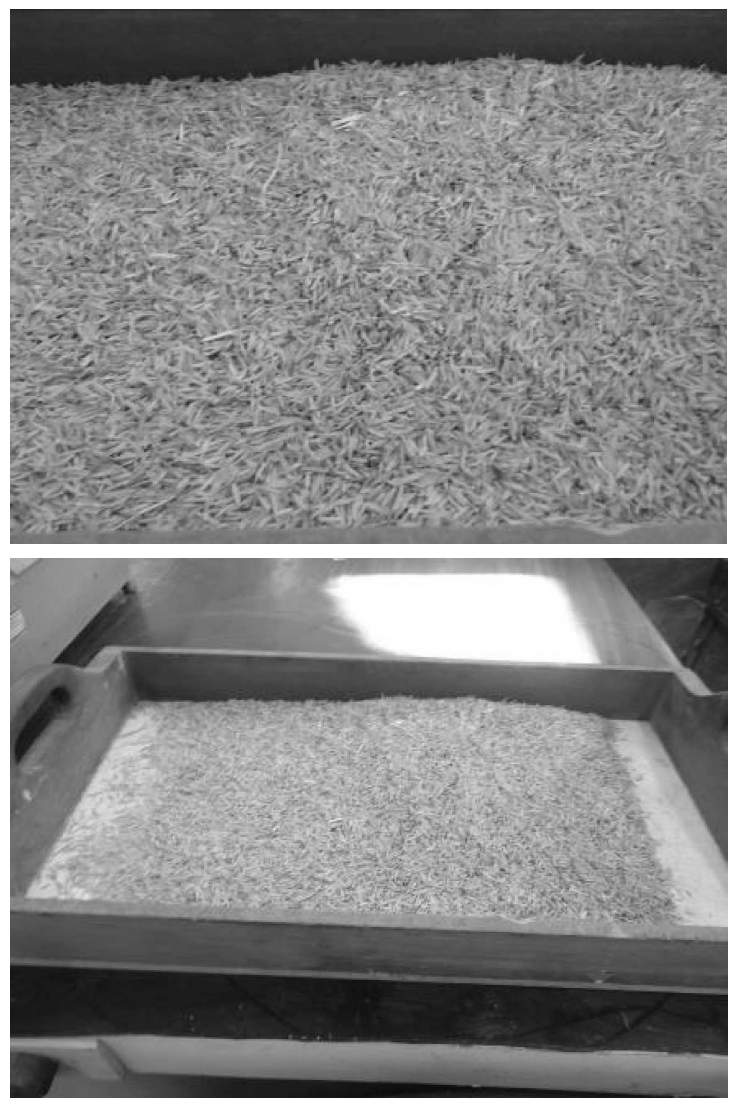

Fig. 3. Rice husk: waste received (top) and after cleaning (bottom).

\subsection{Production of mortar}

A selection of particles was carried out by preliminary screening using a sieve of $4.8 \mathrm{~mm}$ opening. This allowed the separation of materials, ensuring that particles larger than this dimension should be discarded, thus generating samples of aggregates that can provide blends with higher uniformity and higher workability.

The trace of mortar that was used in this study consisted of $1: 4$ (cement: sand) by volume. The consistency index pattern was fixed at $260 \mathrm{~mm} \pm 5 \mathrm{~mm}$ measured in the table consistency for the reference mortar. Experimental dosages with different amounts of cement (CP-IV), medium sand, and water were applied in separate mortars made with substitution of sand by waste until the proper consistency indexes were achieved.

The mortar composites had a curing time of 28 days and during the first $48 \mathrm{~h} \pm 24 \mathrm{~h}$ they remained in the molds in a climatic chamber with controlled temperature and relative humidity $\left(T=20^{\circ} \mathrm{C} \pm 2{ }^{\circ} \mathrm{C}\right.$,
$R H=70 \% \pm 10 \%)$ in the same room. After this period, the samples were demoulded and stored in containers with water and lime, in conditioned room, where they remained until fully cured. The pores influence the acoustic behaviour, therefore important for the healing of mortars and water content. After this period, they were removed from the water and stored in conditioned room until to stabilize the moisture and achieve constant mass, adopting the parameter of variation below $1 \%$ between measurements. They were weighted and measured, calculating sample density (in $\mathrm{kg} / \mathrm{m}^{3}$ ).

For all mortars produced we used the same procedure, without significant differences among mortars with different dosages of waste. We found minor differences among preparation of regular mortars and mortars with waste components.

\section{Results and discussion}

\subsection{Absorption coefficients}

\subsubsection{Comparison between configurations with dosage of $5 \%$}

In Fig. 4, the graph shows the results of the sound absorption obtained for the dosing of mortars with $5 \%$ for different residues at frequencies tested. Examining the data, it can be seen that very approximate values were obtained in rice husk and counter shoes mortars. In both samples, the highest value of absorption coefficient occurred around $2 \mathrm{kHz}$, with 0.10 absorption coefficient. When using the residue of plywood, we found values of absorption coefficients larger than the previous ones, at almost all frequencies measured. However, for the three residues, the measured absorption did not exceed 0.10. Apparently the dosage of $5 \%$ addition of residue in the composites has little influenced on acoustic absorption, approaching the values found in the reference sample.

\subsubsection{Comparison between configurations with dosage of $10 \%$}

In Fig. 5, the graph shows the values of sound absorption corresponding to $10 \%$ dosage. It is observed that the values of sound absorption to counter residues and rice husk are approximate, with sound absorption coefficient between 0 and 0.10 . Plywood results are slightly higher, reaching a 0.13 absorption coefficient at $1.6 \mathrm{kHz}$, and rice husk has an increase at higher frequencies, with a 0.22 at $2 \mathrm{kHz}$.

\subsubsection{Comparison between configurations with dosage of $25 \%$}

In Fig. 6, the graph shows the results found in the sound absorption coefficients configuration with $25 \%$ waste. It appears that the results of the residue of plywood showed more significant results, but the other 


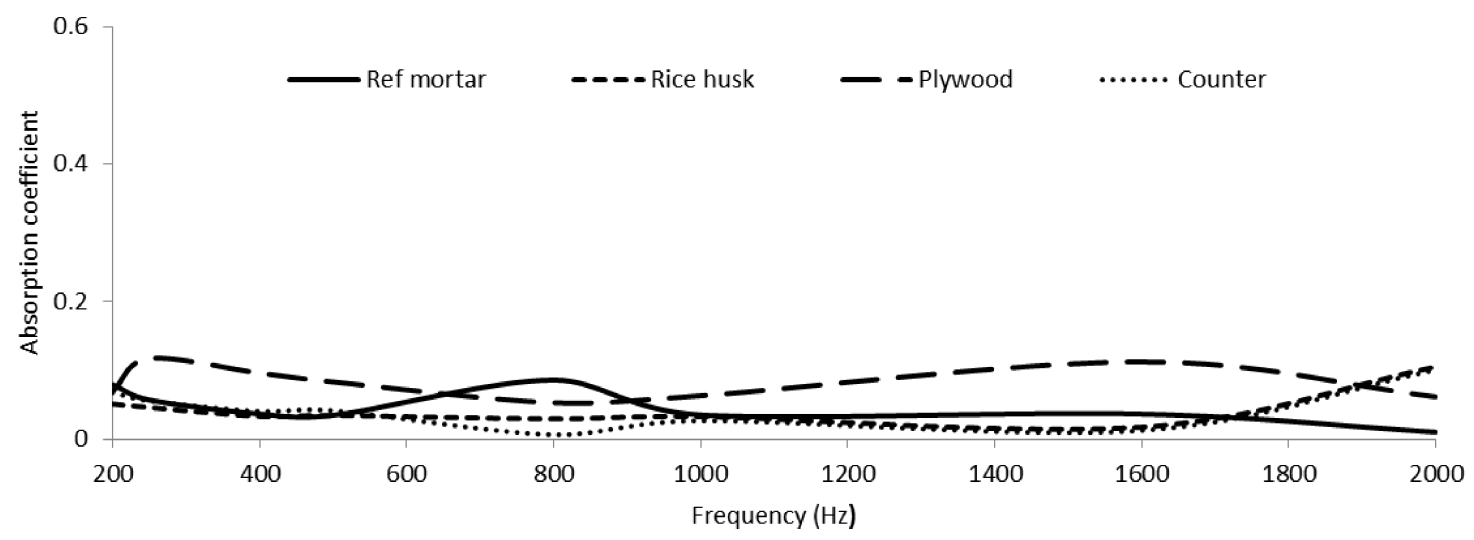

Fig. 4. Sound absorption coefficients - mortars with $5 \%$ of waste.

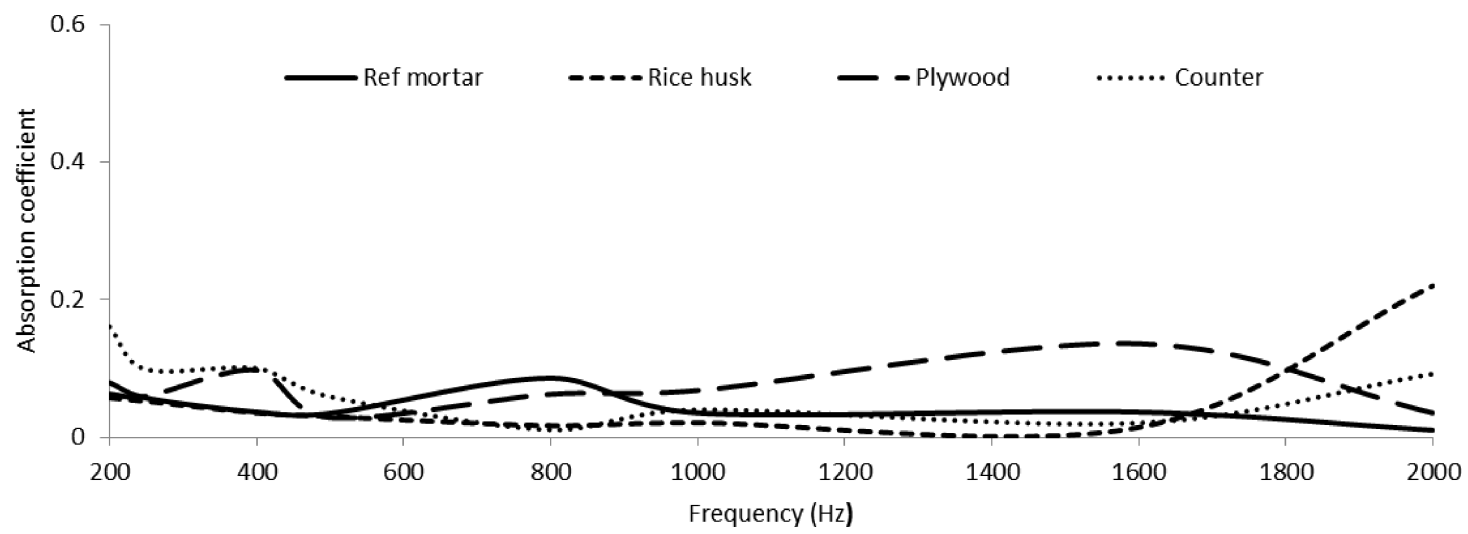

Fig. 5. Sound absorption coefficients - mortars with $10 \%$ of waste.

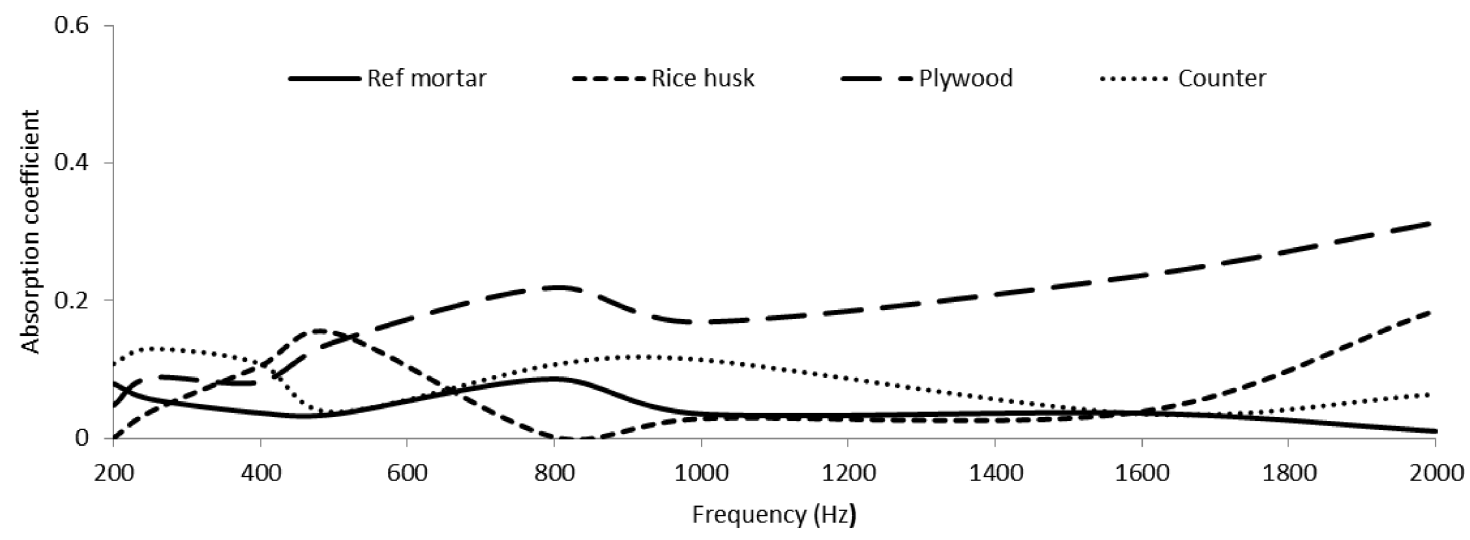

Fig. 6. Sound absorption coefficients - mortars with $25 \%$ of waste.

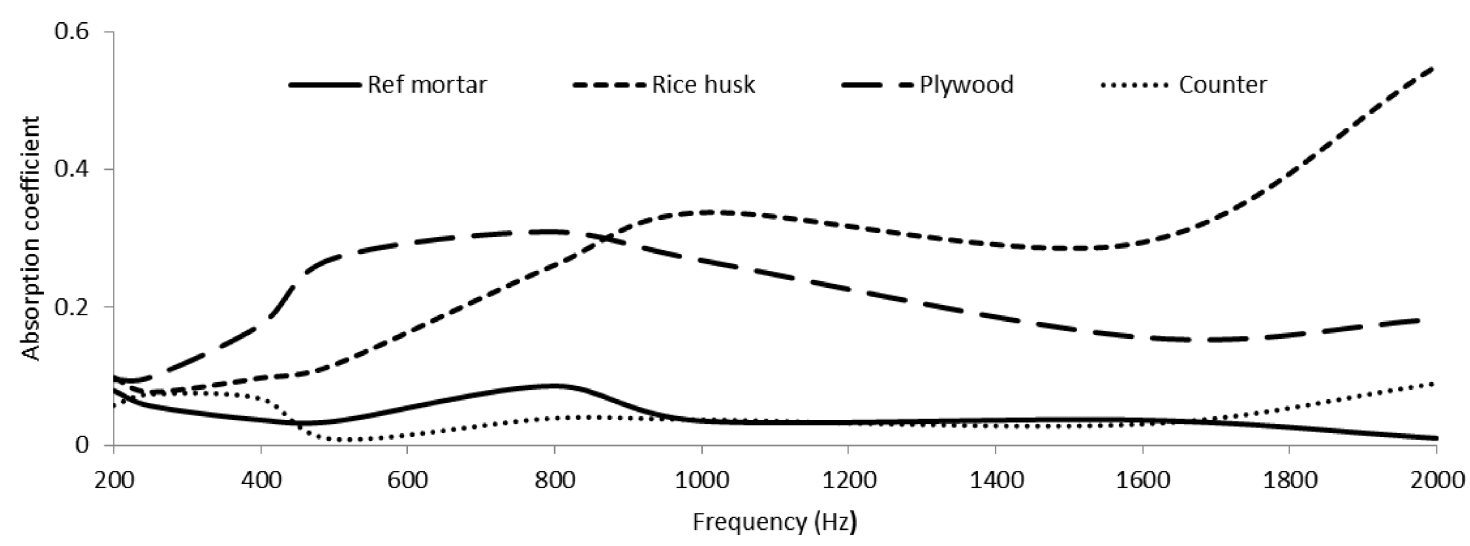

Fig. 7. Sound absorption coefficients - mortars with $50 \%$ of waste. 
residues showed some resemblance. The counter mortar values are above the reference found in the mortars. Therefore the dosage of $25 \%$ represents a significant increase in sound absorption of the composites, reaching absorption coefficient values of about 0.30 for plywood.

\subsubsection{Comparison between the configurations with a dosage of $50 \%$}

Values obtained for the dosing of $50 \%$ with various residues are presented in Fig. 7. The addition of fibers increases the behaviour of the samples. It has a reasonable increase in the absorption coefficient at higher frequencies, with peak absorption coefficient of 0.30 at $600-800 \mathrm{~Hz}$ for plywood, and 0.34 at $1 \mathrm{kHz}$ and 0.55 at $2 \mathrm{~Hz}$ for rice husk. Results showed lower performance of shoe counter mortar, staying close to the reference mortar. In general, mortars with $50 \%$ waste have the major absorption coefficients.

\subsubsection{Noise Reduction Coefficient (NRC)}

Noise Reduction Coefficient (NRC) provides an overview of the results. NRC values are shown in Table 1 for reference mortar and samples with waste of plywood formwork, rice husk, and shoe counters. The reference configuration reached a $\mathrm{NRC}=0.0343$. It should be noted that this configuration was as expected, because there are studies that found that similar mortars showed a NRC $=0.0375$ (BISTAFA, 2006)

Table 1. Noise Reduction Coefficient (NRC).

\begin{tabular}{|l|c|c|c|c|c|}
\hline \multirow{2}{*}{ Waste type } & \multicolumn{5}{|c|}{ Waste dosage } \\
\cline { 2 - 6 } & $0 \%$ (ref.) & $5 \%$ & $10 \%$ & $25 \%$ & $50 \%$ \\
\hline Rice husk & & 0.0546 & 0.0863 & 0.1014 & 0.2757 \\
\hline $\begin{array}{l}\text { Plywood } \\
\text { formwork }\end{array}$ & 0.0343 & 0.0813 & 0.0478 & 0.1773 & 0.2052 \\
\hline Shoe counters & & 0.0561 & 0.0723 & 0.0864 & 0.0523 \\
\hline
\end{tabular}

At $5 \%$ of residuals, the NRC found shows the greatest value for plywood samples $(\mathrm{NRC}=0.0813)$. For $10 \%$ dosage, the NRC demonstrate that the rice husk $(\mathrm{NRC}=0.0863)$ showed greater performance. With $25 \%$ level, it was observed that the plywood mortar appeared highlighted $(\mathrm{NRC}=0.1773)$. Finally, when dosage of waste was $50 \%$, the comparison of the composites indicated that the rice husk $(\mathrm{NRC}=0.2757)$ is offset above the resin $(\mathrm{NRC}=0.2052)$ and shoe counters $(\mathrm{NRC}=0.0523)$. In all cases, composites with waste were superior to reference mortar in terms of sound absorption.

\subsection{Statistical analysis}

We have not found in the literature any studies about absorption coefficient with statistical anal- ysis, either using the techniques of analysis of variance (ANOVA) or regression analysis to prove their results. We investigated variable relationship through regression, creating a statistical model with which the behavior of NRC can be analyzed using a set of independent variables. Independent variables were: Dosage (in \%), Density (in $\mathrm{kg} / \mathrm{m}^{3}$ ), and Type of waste. The Type was codified as a numeric variable, ranging from 0 to 3 . Rice husk was considered as the residue with best acoustic performance, therefore it was assigned the value of 3 , followed by plywood with value 1.5 , shoe counters with the value 1 and, finally, reference mortar to the value zero. This scale was determined through simulations. The resulting model was the following:

$$
\begin{aligned}
\mathrm{NRC}=0.34114- & 0.000165 \cdot \text { Density } \\
& +0.02936 \cdot \text { Type of Waste. }
\end{aligned}
$$

The model was investigated according to the traditional procedures in regression analysis with good results. The analysis of variance using the $F$ test showed significance above $95 \%$ level. Variable analysis performed by $t$ test indicated that the Type and Density influence the NRC, while Dosage not significantly affects NRC, because this variable showed no significance at least $95 \%$ in the t test, and it remains out of model (1). The coefficient of determination $\left(\mathrm{R}^{2}\right)$ of the model was 0.69542 , demonstrating that near $70 \%$ of the NRC variations are explained by the model (Eq. (1)). Therefore we can conclude that the regression model is significant and the statistical analysis confirms the results presented above.

\subsection{Economic analysis}

An analysis of the economic perspective of mortar produced with waste is necessary to verify the viability of these composites. Table 2 presents a survey of costs for conventional materials (glass wool and acoustical foam) and the reference mortar. For the residues incorporated was considered a relative value spent on work and electricity for drying, cutting, and grinding the materials. We considered the cases with $50 \%$ substitution for waste, because they have shown the best

Table 2. Survey of costs of conventional materials and composites studied.

\begin{tabular}{|l|c|}
\hline \multicolumn{1}{|c|}{ Material } & $\begin{array}{c}\text { Costs } \\
\text { (in Euros } / \mathrm{m}^{3} \text { ) }\end{array}$ \\
\hline Glass wool & 274.19 \\
\hline Acoustic foam & 453.63 \\
\hline Reference mortar & 115.32 \\
\hline Mortar with 50\% plywood waste & 80.40 \\
\hline Mortar with 50\% rice husk & 79.53 \\
\hline Mortar with 50\% shoe counter waste & 80.30 \\
\hline
\end{tabular}


acoustic results. There is an advantage when using the composite in view of the cost far below the conventional mortar, representing a saving, besides that it improves reuses and recycling, and reduces costs of waste deposal in landfills.

\subsection{Discussion}

Measurements of sound absorption coefficient show that all configurations with partial substitution of sand by residues $(5 \%, 10 \%, 25 \%$, and $50 \%$ ) had values of sound absorption superior to the composite reference, with similar distributions among them in the whole frequency range.

Apparently, the residues may interfere in sound absorption in mortar with waste. The results indicated that the plywood's NRC are superior to other waste, in settings of $5 \%$ and $25 \%$, the values found to counter top at a dosage of $10 \%$, and to rice husk at a dosage of $50 \%$. Given the characteristics of waste, it was expected that the higher the percentage of residue added to the composite, the apparently greater number of cavities in the face of the composites and therefore, the greater sound absorption will be occurred. So, it can be assumed that the physical configuration (coming from the spaces cavities, pores, and structures of the fiber waste) influences the sound absorption. This hypothesis has support in the analysis of acoustic absorption of waste plywood resin and rice, as opposed to the shoe counter waste, which is impregnated by resin.

In the statistical analysis of regression, the variable Density had become more significant, followed by the variable Type of waste. Thus, it was also observed that the lower mass density, the higher the value of the NRC, therefore more embedded in the mortar residues potentially greater the sound absorption (within the limits investigated). This analysis shows that rice husk performance is up to three times greater when compared to the performance of composites with shoe counters and two times greater when compared to the composite using plywood.

\section{Conclusion}

This research produced mortars with regular cement and sand, with partial replacement of sand by waste, generating samples for analysis in the impedance tube, in 200-2000 Hz frequency range. Results show that the mortars with addition of waste have acoustic absorption above the reference specimens, giving this way an increase in sound absorption ability of these compounds. It is easy to prepare waste and to mould the mortars, and costs for incorporation of these residues are relatively low. Therefore, it was found that the present work to obtain satisfactory performance of composites with different residues with characteristics that qualify with potential for sound absorption, may be a sustainable option to use in the construction industry.

\section{Acknowledgments}

The authors wish to thank to Brazilian Research Councils CAPES, CNPq, and FAPERGS, as well as to UNISINOS to support the development of this project.

\section{References}

1. ABNT - Brazilian Standards Institute (2010), NBR15575-1 - Performance of residential buildings up to five floors, Part 1: General requirements [in Portuguese], ABNT, Rio de Janeiro.

2. Bistafa S.R. (2006), Acoustics applied to noise control [in Portuguese], Edgard Blücher, Sao Paulo.

3. Branco F.G., Godinho L., Tavares J.A. (2010), Use of light mortars on reducing floor impact noise transmission [in Portuguese], Proceedings of 3rd Portuguese Conference on Construction Mortars, APFAC, Lisbon.

4. Del Rey R., J., Alba J., Ramis J., Sanchís V.J. (2011), New acoustic absorbing materials obtained from plastic bottles waste [in Spanish], Materiales de Construccion, 61, 304, 547-558.

5. Duarte E.A.C., Viveiros E.B. (2007), Acoustic performance on Brazilian residential architecture: Sealing walls [in Portuguese], Ambiente Construído, 7, 3, 159171.

6. Ersoy S., KüÇüK H. (2009), Investigation of industrial tea-leaf-fibre waste material for its sound absorption properties, Applied Acoustics, 70, 215-220.

7. Ferraz R. (2008), Impact noise attenuation on floors of multi-pavement buildings [in Portuguese], Master Thesis, PPGEC, Universidade Federal de Minas Gerais, Belo Horizonte, Brasil.

8. Gerges S. (2000), Noise: Fundamentals and control [in Portuguese], 3rd ed., NR Editora, Florianópolis, Brasil.

9. IBGE - Brazilian National Statistical Institute (2010), Results from Decennial Demographic Census, IBGE, Rio de Janeiro.

10. Kazmierczak C.S., Kern A.P., Santos I.S.S., Ramires M.V.V., Silva H.C. (2003), Thermoplastic of shoes waste from Leather-footwear industry [in Portuguese], [in:] Use of construction waste in residential buildings, Rocha J.C, John V.M., ANTAC, Porto Alegre, Brasil.

11. KIELing A. (2009), Influence of segregation on the performance of mortars with rice husk ash and pozzolans with adsorbent material [in Portuguese], Master Thesis, PPGEC, Universidade do Vale do Rio dos Sinos, Sao Leopoldo, Brasil.

12. Losso M., Viveiros E.B. (2004), Drywall and acoustic insulation: theory versus practice in Brazil [in Portuguese], Proceedings of the 10th Brazilian Conference on Technology of Built Environment, ANTAC, Sao Paulo. 
13. Mehta P.K., Monteiro P.J.M. (2006), Concrete: microstructure, properties, and materials, 3rd ed., McGraw-Hill, New York.

14. Mosmann A.S. (2012), Proposal to use rationalization and waste management of building formwork wood [in Portuguese], Master Thesis, PPGEC, Universidade do Vale do Rio dos Sinos, Sao Leopoldo, Brasil.

15. Oldham D.J., Egan C.A., Cookson R.D. (2011), Sustainable acoustic absorbers from biomass, Applied Acoustics, 72, 350-363.

16. Polli T., Viveiros E.B. (2007), When price no matters: Relationship among building costs and acoustics comfort [in Portuguese], Proceedings of 9th Brazilian Conference on Comfort in Built Environment, ANTAC, Ouro Preto, Brasil.

17. Porges G. (1977), Applied Acoustics, Edward Arnold, London.

18. Ramis J., Alba J., Del Rey R., Escuder E., SANCHís V.J. (2010), New sound absorbers materials based on Kenaf fiber [in Spanish], Materiales de Construcción, 60, 299, 133-143.
19. Rосна J.C., John V.M. (2003), Use of construction waste in residential buildings [in Portuguese], ANTAC, Porto Alegre, Brasil.

20. Sakamoto S., Takauchi Y., Yanagimoto K., WaTANABE S. (2011), Study for sound absorbing materials of biomass tubule etc. (Measured Result for Rice Straw, Rice Husks, and Buckwheat Husks), Journal of Environment and Engineering, 6, 2, 352-364.

21. Tutikian B.F., Nunes M.F.O., Leal L.C., MarQUETTO L. (2012), Impact sound insulation of lightweight concrete floor with EVA waste, Building Acoustics, 19, 2, 75-88.

22. ViannA N.S., Roméro M.A. (2002), Methodology for assessing post-occupancy in low-income housing projects with an emphasis on environmental comfort [in Portuguese], Ambiente Construído, 2, 3, 71-84.

23. YAng H.-S., Kim D.-J., Kim H.-J. (2003), Rice strawwood particle composite for sound absorbing wooden construction materials, Bioresource Technology, 86, 2, 117-121. 